\title{
A TECNOLOGIA, A CIÊNCIA E SEUS MODOS DE PRODUÇÃO: REPRESENTAÇÕES DE PROFESSORES DO ENSINO FUNDAMENTAL
}

\author{
TECHNOLOGY, SCIENCE AND THEIR PRODUCTION MODE: \\ PRIMARY SCHOOL TEACHERS' REPRESENTATIONS
}

TECHNOLOGIE, SCIENCE ET LEUR MODE DE PRODUCTION : LA REPRESENTATION DES MAITRES DE L'ENSEIGNEMENT PRIMAIRE

\author{
LA TECNOLOGÍA, LA CIENCIA Y SU MODO DE PRODUCCIÓN: \\ REPRESENTACIONES DE PROFESORES DE LA ENSEÑANZA FUNDAMENTAL
}

Gilberto Lacerda dos Santos*

\section{RESUMO}

Este trabalho apresenta resultados de uma investigação cujo objetivo foi a explicitação de representaçôes de futuros professores de Ciências de três importantes universidades brasileiras, em formação para atuarem nas quatro primeiras séries do ensino fundamental (licenciandos em Pedagogia) acerca da Ciência, da Tecnologia e de seu modo de produção. As conclusões a que chegamos indicam que os futuros professores de Ciências brasileiros distanciam-se de uma atuação condizente com o Novo Modo de Produção do Conhecimento e que é necessária a adoção de um Novo Modo de Formação, estratégia fundamental para instrumentalizar adequadamente as novas geraçôes para a compreensão do empreendimento científico-tecnológico, novas gerações essas que, por meio do modo tradicional de formação científica e tecnológica, acabam inseridas em um círculo vicioso pautado seja pelo desinteresse sistemático por conteúdos de natureza científica e tecnológica, seja pela incompreensão da natureza social de tais conteúdos.

Palavras-chave: Formação de professores. Ciência e tecnologia. Novo modo de produção do conhecimento.

* Doutor em Educação pela Université de Laval (Canadá, 1995). Doutor em Sociologia pela Universidade de Brasília (UnB, 2001). Professor Associado I da Faculdade de Educação da UnB - DF (glacerda@unb.br). 


\section{A EMERGÊNCIA DE UM NOVO MODO DE PRODUÇÃO CIENTÍFICA ETECNOLÓGICA}

A idéia da emergência de um Novo Modo de Produção do Conhecimento Científico e Tecnológico não é tão recente. Desde a década de 80 , inúmeros autores têm apontado para os indícios do surgimento de uma dinâmica inovadora com relação ao desenvolvimento científico e tecnológico. Essa dinâmica é especialmente baseada no livre fluxo de informaçôes e na comunicação aberta entre diferentes áreas do conhecimento e diferentes setores da sociedade (BOYLE; WHEALE, 1984; HOBSBAWM, 1995; ROSENBERG, 1982; SCHAFF, 1995). Nesta perspectiva, parece-nos existir uma relação diretamente proporcional entre o aumento no fluxo de informações e a dinamização dos processos de produção de conhecimentos científicos e tecnológicos. Essa relação pode ser constatada em diferentes momentos da história da humanidade em que a sociedade foi incrementada com tecnologias de comunicação, como a produção de papiros, na Antiguidade, ou de documentos impressos, na Idade Média, que permitiram, de uma forma ou de outra, o intercâmbio entre comunidades científicas, entre pensadores e pesquisadores, entre civilizaçōes distintas. Um estudo criterioso sobre modificações no fluxo de informações através da História e sua influência no estabelecimento de novos modos de produção de Ciência e Tecnologia constitui uma interessante pista de pesquisa.

Mais recentemente, Santos (2000), em uma interessante reflexão sobre a sociedade globalizada, faz alusão a essa nova dinâmica, ressaltando que a emergência de uma nova história da humanidade é necessariamente tributária de uma nova relação do homem com a Ciência e com as técnicas, baseada principalmente em uma democratização do saber e do acesso à informação e em uma compreensão mais objetiva dos procedimentos de produção de conhecimentos.

Gibbons et al. (1994) delineiam os contornos desse Novo Modo de Produção do Conhecimento, enfatizando que a sociedade está gradativamente migrando de uma dinâmica homogênea para uma dinâmica heterogênea em termos da construção do pensamento científico e tecnológico. Segundo os autores, a explosão de conhecimentos nas duas últimas décadas tem como base um processo de produção compartilhada em que diferentes atores estão envolvidos. O Novo Modo de Produção do Conhecimento (M2), em oposição ao Antigo Modo de Produção do Conhecimento (M1), é pautado pelo aumento da produção de Ciência e Tecnologia, pela agregação de alto valor comercial ao conhecimento produzido, pela heterogeneidade institucional envolvida na produção de conhecimentos, pela aplicabilidade cada vez mais ampla dos conhecimentos, pela necessidade de contextualização de tais conhecimentos, pela transdisciplinaridade, pela instrumentação e pela reflexibilidade.

É importante frisar que a emergência do M2 pode não implicar necessariamente o ocaso do M1. Sobral (2000) aborda esta questão ressaltando que o Novo Modo de Produção do Conhecimento provoca mudanças na pesquisa desenvolvida tradicionalmente 
nas universidades, que era mais disciplinar e se realizava, sobretudo, num contexto acadêmico orientado pelo próprio processo de conhecimento, e não por sua utilidade econômica ou social. No entanto, a consolidação do Novo Modo de Produção do Conhecimento não implica necessariamente a substituição do antigo, além do fato de que, para o seu surgimento, foi importante a implementação do anterior. Eles podem desenvolver-se simultaneamente, dando margem à realização de diferentes tipos de pesquisas, embora a pesquisa básica e a aplicada estejam cada vez mais associadas.

As implicações deste novo cenário apenas começam a ser compreendidas, mas a emergência deste Novo Modo de Produção do Conhecimento gera uma grande demanda por profissionais devidamente capacitados e dotados de uma percepção menos hermética acerca da Ciência, da Tecnologia e das repercussões de ambas sobre a Sociedade. Há, portanto, uma demanda por um "Novo Modo de Formação Científica e Tecnológica", como discutiremos na seção seguinte, à luz de um quadro teórico envolvendo os conceitos de Letramento Científico e Tecnológico (LCT) e as interrelações entre a Ciência, a Tecnologia e a Sociedade.

\section{CIÊNCIA E TECNOLOGIA SOB A ÓTICA DO LETRAMENTO CIENTÍFICO E TECNOLÓGICO}

Atualmente, é difícil imaginar uma discussão sobre as possibilidades de desenvolvimento do mundo moderno, sobre a emergência e eventual consolidação do M2 ou sobre as possibilidades da vida humana no futuro sem se fazer referência à Ciência e à Tecnologia e a seu papel no processo de mudança, o que evidencia as complexas interações entre essas duas "áreas de expressão humana" e a sociedade (BOYLE; WHEALE, 1984). De fato, nos últimos anos, as inter-relações entre a Ciência, a Tecnologia e a Sociedade têm sido apontadas como vitais para o desenvolvimento das nações, principalmente tendo em vista as grandes mudanças estruturais que caracterizam a transição de uma era industrial para uma era eminentemente tecnológica (HOBSBAWM, 1995). Aliás, um dos mais importantes princípios do M2 fundamenta-se justamente na responsabilidade social dos produtores de Ciência e Tecnologia e na reflexibilidade.

Todo esse movimento em direção a uma nova sociedade tem colocado em evidência, entre outros aspectos, o papel da Ciência e da Tecnologia como fatores cruciais para estimular, impulsionar e manter o desenvolvimento socioeconômico dos países. Muitos economistas (principalmente Schumpeter) já demonstraram com clareza essa relação, enfatizando notadamente como inovações tecnológicas podem alimentar o sistema econômico, gerando uma série de novos produtos e fomentando a pesquisa em torno de "novas inovaçôes" (YEARLEY, 1988). Neste sentido, o sucesso econômico das nações passa necessariamente pelo progresso científico e tecnológico, idéia com relação à qual também convergem analistas marxistas. 
A importância atribuída ao letramento científico e tecnológico e ao movimento CTS nos países industrializados surge principalmente em resposta a uma crise generalizada no âmbito da formação científico-tecnológica em todos os níveis de ensino e assinala a necessidade da adoção de um novo modo de formação científica e tecnológica para fazer face ao novo modo de produção. Tal crise é evidenciada, por exemplo, na ineficácia dos métodos de ensino de Ciências, que via de regra perpetuam a idéia de que a prática científica é de natureza elitizada e fechada, desinteressando as novas geraçôes, esvaziando os cursos científicos universitários e comprometendo projetos nacionais de desenvolvimento científico e tecnológico em médio e longo prazo. Sobre a dimensão desta crise, a Unesco revelou um quadro preocupante em escala mundial durante o Fórum do ano 2000, realizado em 1993, que enfatizou principalmente a falta de pertinência dos modelos de educação científica atualmente em voga (MORGAN, 1993; SOLTMAN, 1993).

No caso do Brasil, tal situação é bastante grave, vem sendo perpetuada e, a nosso ver, compromete fortemente os propósitos nacionais de inserção do País na sociedade tecnológica emergente e no Novo Modo de Produção de Conhecimentos. Trata-se de uma dinâmica viciosa que tem sua gênese na escola fundamental, onde a criança em fase de início de escolarização tem contato pela primeira vez com conhecimentos sistematizados acerca da Ciência e da Tecnologia, conforme prevêem inclusive os Parâmetros Curriculares Nacionais (BRASIL, 1997). No entanto, tal prescrição é via de regra inviabilizada pelos próprios professores responsáveis por tal iniciação científica. Oriundos de faculdades de educação, onde recebem uma formação generalista, os pedagogos que atuam nas quatro primeiras séries do ensino fundamental têm como característica o fato de terem se distanciado, ao longo de toda sua formação escolar e universitária, das Ciências Naturais (Física, Química, Biologia). Conseqüentemente, tais profissionais docentes abordam o ensino de Ciências de modo inadequado, reproduzindo traumas, equívocos e representações herméticas que eles próprios detêm enquanto indivíduos. Estes dados empíricos, provenientes de vários anos de observações não sistematizadas na disciplina "Ciências Para Início de Escolarização", na Faculdade de Educação da Universidade de Brasília, evidenciam a existência de um quadro preocupante, que faz com que os futuros professores acabem por desenvolver em seus alunos um certo temor pelas áreas científicas que se perpetua ao longo de toda a escolarização até o ensino de nível superior, onde os cursos relacionados com essas áreas se esvaziam cada vez mais.

Diversas pesquisas acerca das representações de professores sobre a Ciência (BERTHELOT, 1987; DÉSAUTELS; LAROCHELLE, 1995) e sobre a Tecnologia (SANTOS, 1997) têm revelado essa situação problemática. Essas pesquisas enfatizam a necessidade crucial de se avançar na melhoria do ensino científico e tecnológico como estratégia para o desenvolvimento sustentável, o que evidencia a dimensão socioeconômica da referida crise, conforme enfatizam Walks (1986) e a American Association for the Advancement of Science (1989; 1993), através dos documentos oficiais Science for All Americans e Project 2001. De acordo com tais publicaçôes, que se referem exclusivamente 
ao contexto dos países desenvolvidos, professores e cientistas têm constantemente enfatizado a incontestabilidade da relação entre Ciência, Tecnologia e poder, e anunciado que a diminuição crescente de cientistas nos países do hemisfério norte e que a ausência de uma sólida cultura científica e tecnológica no seio da população são fatores absolutamente ameaçadores para o Ocidente.

A inquietude com relação à formação científica e tecnológica das novas gerações não é recente. Desde os anos 50, quando do lançamento da Spoutinik pelos russos, os países ocidentais começaram a desenvolver programas e a formalizar políticas de formação científica e tecnológica, voltados notadamente para objetivos político-econômicos, tendo em vista a Guerra Fria, em detrimento de objetivos sociais e culturais, tendo em vista necessidades humanas. Conseqüentemente, tais ações tinham como objetivo principal a formação de uma elite científica e tecnológica capaz de fazer triunfar, especialmente, a "civilização" estadunidense. Tal meta foi amplamente atingida através da adoção de um sistema de formação baseado em sucessivas especializações, cujos resultados foram bastante positivos em curto prazo. No entanto, em longo prazo os resultados desse modelo demonstraram que, de um lado, a população em geral mantinha-se bastante distanciada da prática científica, hierarquizada e especializada por natureza, deixando aos ditos especialistas o privilégio e a responsabilidade de determinar os rumos da sociedade em termos de Ciência e Tecnologia. Por outro lado, e como conseqüência da situação anterior, os resultados demonstraram que a elitização da Ciência e da Tecnologia acabou por conduzir a sociedade como um todo na direção de problemas cruciais, incontornáveis e relacionados com a própria sobrevivência da espécie humana, como a degradação do meio ambiente, a destruição da camada de ozônio, o aquecimento global, a poluição, a acentuação desmedida do desequilíbrio sócio-econômico mundial, o desaparecimento de espécies animais etc.

Como já mencionamos anteriormente, é nas séries iniciais do ensino fundamental que a criança é introduzida ao estudo e à compreensão da Ciência e da Tecnologia como fenômenos socialmente construídos e contextualizados (BIZZO, 2001). Neste sentido, é evidente que o profissional docente atuando nessas séries tem uma responsabilidade importante com relação ao interesse futuro do indivíduo pela Ciência e pela Tecnologia. Vejamos o que nos ensina a teoria didática acerca do modo de funcionamento do profissional docente, no contexto da relação educativa.

$\mathrm{Na}$ medida em que desempenha sua função reguladora e intermediadora entre o saber do aluno e o saber do conteúdo, o professor de Ciências age como um elemento de ligação entre conhecimentos formalmente delimitados (em função de premissas epistemológicas) e versões didáticas desses mesmos conhecimentos (em função de premissas pedagógicas inerentes ao processo de ensino-aprendizagem). Nesse processo de transposição didática de conhecimentos (CHEVALLARD, 1991), o professor tem a responsabilidade de assegurar que o conhecimento formal seja traduzido segundo uma 
versão didática adequada e válida, suscetível de ser tratada como matéria de ensino e como objeto de aprendizagem. Para tanto, ele precisa ter estabelecido relações prévias com tal conhecimento, tê-lo compreendido do ponto de vista externo e interno. Em resumo, ele precisa conhecer a matéria a ser ensinada, se aproximando de sua lógica de produção, de seus sistemas de tratamento, de representações e de significações.

Nos últimos anos, diversas pesquisas têm se voltado para apontar a relação estreita existente entre as representaçōes e crenças de professores de Ciências acerca do conhecimento científico e o modo como tal conhecimento é transmitido por esses professores através de programas escolares (BRUZZI, 1995; CRONIN-JONES, 1991; DÉSAUTELS et al., 1993; GUILBERT; MELOCHE, 1993; KRASILCHIK, 1987; MCDERMOTT, 1990; MORENO MARINON, 1986). Via de regra, tais estudos têm apontado, direta ou indiretamente, que os professores de Ciências detêm representações equivocadas sobre a Ciência, seu modo de produção e suas relações com o meio social. Tais representações são oriundas do senso comum e construídas mediante relações individuais conflituosas com esse conhecimento, supostamente tão hermético, elaborado, de difícil acesso e compreensão. Elas têm repercussões muito negativas sobre a formação das novas gerações, na medida em que parecem criar e estabelecer uma espécie de círculo vicioso centrado no estabelecimento de uma fronteira protocolar, muitas vezes intransponível, entre o cidadão comum e o mundo da Ciência e da Tecnologia.

$\mathrm{Na}$ medida em que fixamos nossa atenção sobre os professores das séries iniciais do ensino fundamental, percebemos que a situação é bastante complexa e grave. A grande maioria desses profissionais docentes, que têm a função social de introduzir a criança na dinâmica das interaçôes com o saber através da escola, distanciaram-se ou foram distanciados, ao longo de sua formação escolar, de conteúdos de natureza científica e tecnológica; descartaram de suas vidas e de seus projetos profissionais, por razões socioeconômicas diversas, toda e qualquer abordagem da Ciência e da Tecnologia e, conseqüentemente, evitam ou simplificam ao máximo o tratamento de tais conteúdos na escola fundamental. No entanto, é a esse indivíduo, uma vez formado e inserido no mercado de trabalho, que a sociedade atribui a responsabilidade de despertar o interesse da criança pela Ciência e pela Tecnologia e de fazê-la iniciar a compreensão dos complexos e intrincados processos de produção do conhecimento, compreensão essa que constitui o embriāo da formação do cidadão para operar no contexto do M2.

Mas, como pode o pedagogo intermediar a transposição de saberes que, para ele, constituem uma verdadeira caixa preta, são inabordáveis em sua essência, indiscutíveis em sua forma e inexoráveis em seus efeitos? Como pode esse profissional docente desmistificá-los junto a seus alunos? Que transposição de conhecimentos poderá ele operar se os conhecimentos em questão sequer são percebidos como tal e se o indivíduo não é visto como parte ativa e determinante com relação aos inputs e aos outputs do sistema científico-tecnológico? 
Temos aí questôes que delimitam uma situação problemática demandando estudos para que a sociedade como um todo possa construir representações mais amplas e nítidas com relação à Ciência e à Tecnologia e a seu processo de produção, para que possamos compreender que tais conhecimentos são produzidos através de tramas complexas envolvendo cientistas, inventores, tecnólogos, industriais, consumidores, políticos etc., e que eles não vêm de fora da sociedade, mas de seu interior, justamente como fatores suscetíveis de transformá-la, apresentando dimensões econômicas, culturais, ideológicas, políticas e científicas que os situam no centro de processos sociais igualmente complexos. E é justamente dessa contraposição entre as novas demandas sociais com relação ao M2 e a aparente incapacitação dos professores do ensino fundamental para introduzir a criança no contexto cognitivo que caracteriza esse modelo que toma forma o presente trabalho, cujo desenvolvimento implicou a explicitação de representações de professores acerca da Ciência e da Tecnologia, representaçôes estas que podem comprometer a emergência de uma cultura científica e tecnológica necessária para apoiar a instauração do Novo Modo de Produção do Conhecimento previsto por Gibbons et al. (1994).

\section{METODOLOGIA DE INVESTIGAÇÃO ADOTADA}

Tendo em vista a configuração da situação problemática apresentada, muitos avanços têm sido feitos no sentido de se desmistificar a Ciência, a Tecnologia e seu processo de produção junto aos professores de Ciências das séries iniciais do ensino fundamental. Sem negligenciar as condiçôes cognitivas, áreas de estudos como a Didática das Ciências, a Sociologia da Ciência e a Filosofia da Ciência têm evidenciado, de maneira sistemática, as condições sociais da produção da Ciência e da Tecnologia (CARVALHO; GIL-PÉREZ, 1993; CHALMERS, 1986; FOUREZ, 1995; KNORR-CETINA, 1981). Existe, portanto, uma grande expectativa de que, em função desta "virada epistemológica", o professor de Ciências ${ }^{1}$ possa compreender que a produção científico-tecnológica e a aplicação de seus resultados são ações humanas impregnadas de significações éticas, políticas, econômicas e culturais, que não podem ser ignoradas na medida em que se tem em mente a edificação de uma sociedade minimamente viável e auto-sustentável, palavras-chave incontornáveis para se definir a sociedade nova em que adentramos e para se redefinir a formação escolar das novas gerações.

O ponto de partida da investigação foi a elaboração de uma hipótese de trabalho segundo a qual os alunos de cursos de licenciatura em Pedagogia, futuros professores de Ciências do ensino fundamental, desconhecem o jogo da produção e da difusão da Ciência e da Tecnologia e estabelecem uma relação hermética e formal com conteúdos relacionados com essas áreas. Conseqüentemente, eles atribuem a esses conhecimentos o mesmo estatuto epistemológico atribuído ao conhecimento oriundo do senso comum em seu sentido "natural", isto é, relacionado com o conhecimento científico bastante vulgarizado, como a fórmula da água ou a noção de célula, que, de tão difundidos na 
sociedade, parecem independer da intervenção humana, estando circunscritos à esfera do consumo não-reflexivo. Neste sentido, a Ciência e a Tecnologia seriam percebidas como elementos mistificados e mistificadores, cabendo então aos indivíduos envolvidos com a sua produção e manejo um estatuto social diferenciado, exatamente como acontece com aqueles que lidam com saberes oriundos do senso comum em seu sentido "sobrenatural", isto é, de natureza mística, mágica e religiosa. Considerando-se o exposto, o científico e o tecnológico seriam vistos por esses professores como elementos naturais e óbvios, o que os isentaria de críticas e desresponsabilizaria o cidadão comum.

Para subsidiar o desenvolvimento do trabalho, foram abordados em entrevistas coletivas 60 professores em formação, em universidades de três regiōes do Brasil: CentroOeste (Universidade de Brasília), Nordeste (Universidade Federal do Ceará) e Sudeste (Universidade Federal de Minas Gerais). O trabalho de explicitação de representação foi elaborado a partir dos estudos sobre representações sociais de Jodelet (1991) e Moscovici (1978; 1984). O estudo de representaçôes proposto, da história cultural de um grupo com relação a um tema específico, será desenvolvido à luz do conceito de "representação social" formulado em 1961 pelo francês Serge Moscovici, em um estudo sobre concepções coletivas acerca da Psicanálise. Para avançar em sua conceituação, Moscovici retomou e renovou o conceito de "representação coletiva" formulado por Durkheim, para quem a compreensão da maneira como a sociedade se representa a si e ao mundo passa pela compreensão da natureza da sociedade, e não da natureza do indivíduo, pelas concepçōes dos grupos, e não pelas dos particulares (DAUSTER, 2000). Para Durkheim (1978, p. 79),

... as representaçôes coletivas traduzem a maneira como o grupo se pensa nas suas relaçóes com os objetos que o afetam. Ora, o grupo é constituído de modo diferente do indivíduo e as coisas que o afetam são de uma outra natureza. Logo, representaçôes que não exprimem nem os mesmos sujeitos, nem os mesmos objetos não poderiam depender das mesmas causas. Para compreender a maneira como a sociedade se representa a si própria e ao mundo que a rodeia, precisamos considerar a natureza da sociedade e não a de particulares.

Como enfatiza Alves-Mazzotti (2000), Moscovici vai buscar no método durkheimiano, cujo espírito está resumido na citação acima, elementos teóricos que lhe permitem estabelecer um modelo capaz de dar conta dos mecanismos psicológicos e sociais que atuam na produção de representaçôes, as quais dizem respeito a uma família de conceitos - ideologia, visão de mundo, idéia-força, mito, utopia - e que se referem a uma elaboração teórica complexa, que por sua vez não somente reflete relações sociais mas também contribui para as solidificar.

Ora, como sugerem algumas pesquisas já mencionadas, que estudam representações de professores sobre a Ciência (BERTHELOT, 1987; BRUZZI, 1995; CRONINJONES, 1991; DÉSAUTELS; LAROCHELLE, 1995; DÉSAUTELS; LAROCHELLE; GAGNÉ; RUEL, 1993; GUILBERT; MELOCHE, 1993; KRASILCHIK, 1987; MCDERMOTT, 1990; MORENO MARINON, 1986), essas representações são de tal 
modo integradas ao sistema cognitivo do indivíduo que ele nelas crê e as reproduz com a segurança da formulação de "verdades universais", de teorias coletivas sobre o real, sistemas que têm uma lógica e uma linguagem particulares, uma estrutura de implicações baseada em valores e conceitos que "determinam o campo das comunicaçôes possíveis, dos valores e das idéias compartilhadas pelos grupos e regem, subseqüentemente, as condutas desejadas ou admitidas" (MOSCOVICI, 1978, p. 51).

\section{REPRESENTAÇÕES DOCENTES COMO EMPECILHOS PARA A INSTAURAÇÃO DO M2}

Analisadas detalhadamente, as representações obtidas revelaram-nos uma certa apatia por parte dos professores em formação e um certo nível de desconhecimento acerca do mundo da Ciência e da Tecnologia e de sua influência nas condições de existência humana. Proposiçôes epistemologicamente distintas obtiveram adesão total dos respondentes, o que os situa em uma certa confusão conceitual delineada pelo próprio sistema de formação do qual somos todos oriundos. No entanto, mesmo que a receptividade a tais proposições fosse mais coerente, elas encerram em seu enunciado uma visão bastante tradicional de Ciência e Tecnologia, ainda relacionada com modos tradicionais de produção do conhecimento, com modos tradicionais de aquisição de conhecimentos, em que as características citadas acima, todas emprestadas do M2 anunciado por Gibbons, não têm espaço nem vez. Isso pode ser explicado porque o M2 já está se consolidando nos países desenvolvidos, mas está apenas emergindo no Brasil.

Ficou igualmente claro nos dados coletados que muitas vocações científicas são sufocadas por causa de condições socioeconômicas e pela existência de um círculo vicioso que faz com que professores de Ciências despreparados sejam responsáveis por despertar nas novas geraçôes o interesse pela Ciência e pela Tecnologia, função a ser exercida pelo próprio público-alvo deste trabalho. Trata-se de um problema que consideramos grave, ignorado pelas políticas públicas, que remete aos princípios fundamentais evocados pelos teóricos do campo da CTS (Ciência-Tecnologia-Sociedade), segundo os quais a participação efetiva do cidadão na Sociedade da Informação (LÉVY, 1999) não depende unicamente de fatores quantitativos relacionados à democratização do conhecimento científico e tecnológico, mas também, e principalmente, de fatores qualitativos relacionados à natureza dos conhecimentos construídos pelo cidadão acerca da Ciência e da Tecnologia.

Outra conclusão semelhante nos dois trabalhos diz respeito à imagem detida pelo público acerca do cientista, da Ciência e da Tecnologia. Os estudantes consultados continuam percebendo o cientista como alguém especial, culto, desprendido, dotado de saberes e "poderes" especiais, relacionados com a inovação, com as descobertas, com as invenções. Nesta mesma ordem de idéias, a Ciência e a Tecnologia continuam a ser representadas como entidades essencialmente benéficas, inquestionáveis, mitologizadas, 
distanciadas do quotidiano imediato das pessoas, mas cujas conquistas têm repercussōes positivas diretas sobre a vida de todos e de cada um.

A constatação de que o Novo Modo de Produção do Conhecimento necessita, para se firmar, de indivíduos imbuídos de representações qualitativamente diferenciadas acerca da Ciência e da Tecnologia emerge de si mesma e já foi abordada no Capítulo I. No entanto, é igualmente evidente que o F2 não está emergindo na mesma velocidade que o M2, este último ainda bastante embrionário no contexto brasileiro. Igualmente, é claro que o Modo de Formação Tradicional F1, condizente com o M1, perpassa ainda e com bastante intensidade a maior parte das iniciativas no campo da produção científica e tecnológica, sobretudo em países com a configuração socioeconômica do nosso, fenômeno de conseqüências obviamente negativas com relação ao avanço do País no cenário do M2.

Vários estudos, alguns deles referenciados neste trabalho, costumam focar o meio universitário como fator importante na resistência ao surgimento de novos modos de produção de conhecimentos. No entanto, os dados apresentados e discutidos no capítulo anterior permitem que a problemática seja igualmente situada no ensino fundamental, ponto de partida para a futura formação universitária em Ciência e em Tecnologia. De fato, as instituiçôes de ensino em geral e as de nível fundamental em particular, tal qual funcionam atualmente, parecem constituir importante locus de resistência, diríamos até de impedimento, à instauração de um Novo Modo de Produção do Conhecimento. $\mathrm{E}$ as representaçōes dos estudantes consultados nesta pesquisa, futuros profissionais docentes que atuarão nas séries iniciais do ensino fundamental, corroboram tal idéia.

Tendo em vista que os cursos de formação de pedagogos não privilegiam a formação científica em seus currículos, formação esta normalmente relacionada com, no máximo, duas disciplinas de quatro créditos voltadas para o estudo de metodologias de ensino de Ciências, é necessário questionar sobre as oportunidades que tal público teve, ao longo de sua vida anterior ao nível universitário, para relacionar-se com conteúdos qualitativamente significativos sobre Ciência e Tecnologia.

Vamos imaginar o percurso escolar típico de um desses estudantes, tendo como base dados de identificação dos participantes da TGN e daqueles que responderam ao questionário. Caracterizaremos nosso aluno imaginário como sendo do sexo feminino, oriundo de classe média baixa, filho de pais com baixa escolarização, freqüentando o sistema escolar público, caracterizado por problemas amplamente conhecidos e divulgados: infra-estrutura deficiente, professores despreparados e mal remunerados, material didático inadequado e/ou defasado, inexistência de laboratórios de Ciências Físicas, Químicas e Biológicas e de recursos didáticos como mapas, maquetes, softwares etc.

No ensino fundamental, nossa aluna imaginária é formalmente apresentada à Ciência e à Tecnologia por pedagogos polivalentes, na grande maioria das vezes do sexo feminino, que, até a quarta série, são responsáveis pelo trabalho pedagógico envolvendo 
todas as áreas do conhecimento (Língua Portuguesa, Matemática, História, Geografia, Ciências etc.). E, como também é amplamente conhecido, tais pedagogas, justamente pelo próprio despreparo, concentram sua atuação primeiramente em Língua Portuguesa e, em seguida, em Matemática, deixando de lado as demais disciplinas. Particularmente, a área de Ciências é tradicionalmente conhecida como a "aula do finzinho do dia", por ser uma aula complicada, que desperta muito interesse, em que os alunos manifestam representações espontâneas, muitas vezes bastante contundentes, acerca do ambiente natural. Portanto, ao longo dos quatro primeiros anos de escolarização, nossa aluna tem um contato limitado com questôes de natureza científica e tecnológica, contato este normalmente pautado pelas representações equivocadas de suas professoras. Deste modo, pode-se supor que ela chega ao quinto ano do ensino fundamental totalmente despreparada e imbuída da idéia de que Ciência e Tecnologia são temas difíceis, complicados, extremamente especializados, demandando conhecimentos complexos, distanciados do cidadão comum. Tais representações são reforçadas pela imagem de Ciência e Tecnologia normalmente transmitida pelos diferentes meios de comunicação, como o cinema, a televisão e livros de histórias infantis (DÉSAULTELS; LAROCHELLE, 1995).

No segundo ciclo do ensino fundamental ( $5^{\mathrm{a}}$ a $8^{\mathrm{a}}$ série), nossa aluna imaginária tem acesso a disciplinas específicas de Química, Física e Biologia. Apesar de importantes fatores vocacionais e subjetivos que excluem a possibilidade de linearidade obrigatória neste percurso inventado, neste momento a aluna encontra geralmente grandes dificuldades cognitivas. É importante considerar que os docentes com os quais lida nesta nova fase do ensino fundamental são oriundos de meios universitários tradicionais, como os descritos por Trigueiro e Figueiredo (1998), que também reforçam o hermetismo do campo científico-tecnológico, sendo, portanto, extremamente resistentes à emergência de um Novo Modo de Produção do Conhecimento. Por outro lado, e lembrando que o percurso escolar imaginado tem como cenário meios sociais menos favorecidos, é possível supor que a escola fundamental continua apresentando os mesmos problemas anteriormente evocados.

O momento da passagem do ensino fundamental para o ensino médio é caracterizado, nas classes baixas da população, pela consideração de aspectos tais como localização geográfica da escola média mais próxima, independentemente de sua qualidade ou dos cursos oferecidos, necessidade de ingresso precoce no mercado de trabalho etc. Trata-se de um momento em que o background científico-tecnológico tem um importante papel na decisão a ser tomada pela nossa aluna imaginária. Como ela não se sente "à altura" e não tem condições socioeconômicas para "dar asas" a vocaçôes e aptidōes, ela escolhe a formação para o magistério no turno noturno, como foi o caso de $80 \%$ das alunas participantes da Técnica do Grupo Nominal. Na escola normal, nossa aluna é inteiramente distanciada da abordagem de questôes científicas e tecnológicas, concentrando sua atenção em sua formação profissional, para a qual se supõe que basta conhecer todo um arsenal de metodologias de ensino. 
E chega finalmente o momento do ingresso na universidade. Cursinhos pré-vestibulares são acionados às pressas, fórmulas científicas decoradas sem nenhuma compreensão efetiva, um background cultural é forjado para que nossa aluna possa enfrentar o temido vestibular para Pedagogia, como seu percurso escolar geralmente impõe. Aquelas que conseguem ingresso em instituições públicas passam então a compor o público-alvo desta pesquisa, descrito no segundo e no terceiro capítulo e, uma vez formadas, retornam ao contexto do ensino fundamental, agora como profissionais docentes responsáveis pela formação inicial de novas gerações em Ciência e em Tecnologia.

Para uma configuração mais ampla deste quadro, seria necessário acompanhar o percurso daqueles que conseguem romper o caminho traçado e interessar-se por Ciência e Tecnologia no ensino médio e optar pela formação superior em disciplinas relacionadas com essas áreas. Eis aí uma nova possibilidade de investigação. No entanto, apesar do nosso desconhecimento acerca de dados de pesquisa sobre este tema, é conhecida a problemática do esvaziamento das classes científicas no ensino superior e das concepçōes equivocadas de graduados de áreas científicas acerca da Ciência e da Tecnologia (GUILBERT; MELOCHE, 1993).

Em resumo, a problemática, apesar de suas inúmeras nuances, é a mesma e situa-se na inadequação da formação científica e tecnológica oferecida desde o ensino fundamental, tendo em vista a necessidade, imposta pelo próprio desenvolvimento da sociedade e da adoção de novas formas de relacionamento com a Ciência e a Tecnologia. E, como pode ser percebido, não é apenas o meio universitário que tem que ser responsabilizado pela existência e manutenção desta situação problemática. Todo o sistema de formação tem sua parcela de contribuição para a manutenção de um status quo nocivo, discriminatório e altamente contributório para a instauração de uma sociedade tecnocrática, como diria Fourez (1995).

A resistência à emergência do $\mathrm{M} 2$ pode ser associada à existência de uma significativa e oculta força de oposição ao surgimento de um Novo Modo de Formação, que viria estabelecer novas bases para a relação educativa, relacionadas com a valorização da criatividade, com a autonomia do aluno, com a interação com saberes múltiplos, obtidos em diferentes meios de comunicação. Tal força de oposição ignora que a sala de aula está cambaleante, que os alunos não se interessam mais pelo velho ritmo das aulas, que os próprios professores se sentem desarticulados para, apesar de manter os mesmos discurso e prática tradicionais, estabelecer interações entre a classe e o que se passa fora dela.

Enfim, retomando o raciocínio original, e tendo em vista o exposto, é importante questionar: como pode o professor de Ciências intermediar a comunicação de um conhecimento que, para ele, é uma verdadeira caixa preta, inabordável em sua essência, indiscutível em sua forma e inexorável em seus efeitos, não percebendo que o conhecimento científico e tecnológico é produzido através de tramas complexas envolvendo cientistas, inventores, industriais, investidores, grupos de pressão, consumidores, políticos, etc., e 
que não vem de fora da sociedade, mas de seu interior, justamente como fator suscetível de transformá-la? Que transposição de conhecimentos poderá ele operar se os conhecimentos em questão nem sequer são percebidos como tal e se o indivíduo não é visto como parte ativa e determinante com relação aos inputs e aos outputs do sistema tecnológico? Temos aí questôes que precisam ser respondidas, situações problemáticas que precisam de solução para que a sociedade como um todo construa representaçōes mais abertas e holísticas com relação à Ciência, à Tecnologia e a seu processo de produção.

A análise das concepções que os futuros professores de Ciências constroem a respeito da Ciência e da Tecnologia revela e ratifica uma situação crítica já abordada por muitos autores, principalmente no que diz respeito às relações do público com o conhecimento formal. Via de regra, essa situação crítica é apontada como sendo objeto de interações equivocadas com o conhecimento científico e tecnológico, cuja congruência e interface com a sociedade são raramente estabelecidas. Mas o público não é absolutamente o grande vilão dessa história. A construção de tais representaçôes é igualmente fruto de um complexo jogo de poder, através do qual os resultados dos empreendimentos científico e tecnológico nos são apresentados como sendo fatos consumados e indiscutíveis, como o supra-sumo do avanço do conhecimento, plenos de saberes que estão além de nossa capacidade de compreensão, só nos restando usufruir de seus benefícios. E é evidente que, neste jogo de interesses de comunidades científicas e tecnológicas, econômicas e políticas, laboratoriais e industriais, a alienação do público com relação ao conhecimento é uma variável importantíssima, principalmente tendo em vista que o usufruto dos avanços em Ciência e em Tecnologia se dá no contexto de situaçôes de geração de capital e de consumo de mercadorias. E o grande desafio que têm que enfrentar nossos professores de Ciências é o de lutar para que seus alunos não interiorizem a catastrófica idéia de que eles não são e não podem vir a tornar-se agentes desse processo, jogadores desse intricado jogo, mas apenas peças suscetíveis, inclusive, de serem excluídas do tabuleiro.

\section{Notas}

1. Convém relembrar que a expressão "professor de Ciências" designa, no âmbito do sistema educacional brasileiro, o profissional docente, o pedagogo que atua nas séries iniciais do ensino fundamental ( $1^{\text {a }}$ a $4^{\text {a }}$ série $)$.

\section{Referências}

ALVES-MAZZOTTI, Alda Judith. Representações sociais: desenvolvimentos atuais e aplicações à educação. In: CANDAU, Vera M. (Org.). Linguagens, espaços e tempos no ensinar a aprender. Anais do X Encontro Nacional de Didática e Prática de Ensino, p. 57-73. Rio de Janeiro: DP\&A, 2000. AMERICAN ASSOCIATION FOR THE ADVANCEMENT OF SCIENCE. Project 2001: benchmarks for science education. New York: Oxford University Press, 1993. 
AMERICAN ASSOCIATION FOR THE ADVANCEMENT OF SCIENCE. Science for all americans. Washington: AAAS, 1989.

BERTHELOT, Michel. La conception de la fonction sociale de la science chez les enseignants québécois des sciences du secondaire et du collégial. Relatório de Pesquisa. Université Laval, Québec, Canadá, 1987. BIZZO, Nelio. Ciências: fácil ou difícil? São Paulo: Ática, 2001.

BOYLE, Charles.; WHEALE, Peter. Introduction. In: BOYLE Charles.; WHEALE, Peter.; STURGESS, Bono. People, science and technology, a guide to advanced industrial society. Somerset: The Harvester Press, 1984, p. 1-10.

BRASIL. Ministério da Educação. Enfrentar e vencer desafios. Secretaria de Educação Superior, Brasília: Secretaria de Educação Superior, 2000.

Ministério da Educação. Parâmetros Curriculares Nacionais para o Ensino Fundamental. Brasília: Secretaria de Educação Básica, 1997.

BRUZZI, Rita Carolina Vereza. High school teacher's beliefs and practices about science life-world connections, and the teaching learning process. 1995. Tese (doutorado), Departamento de Currículo e Instrução. The Pennsylvania State University, Pennsylvania, Estados Unidos.

CARVAlHO, Anna Maria Pessoa de; GIL-PÉREZ, Daniel. Formação de professores de ciências: tendências e inovações. São Paulo: Cortez, 1993.

CHALMERS, Alain. A fabricação da ciência. São Paulo: Edunesp, 1986.

CHEVALLARD, Yves. La transposition didactique du savoir savant au savoir enseigné. Grenoble (France): La Pensée Sauvage, 1991.

CRONIN-JONES, Linda. L. Science Teaching biliefs and their influence on curriculum implementation: two case studies. Journal of Research in Science Teaching, New York, v. 38, n. 3, p. 235-250, 1991.

DAUSTER, Tania. Representações sociais e educação. In: CANDAU, Vera M. (Org.). Linguagens, espaços e tempos no ensinar e aprender - Anais do X Encontro Nacional de Didática e Prática de Ensino, p. 49-56. Rio de Janeiro: DP\&A., 2000.

DÉSAUTELS, Jacques; LAROCHELLE, Marie; GAGNÉ, Benoît; RUEL,. Françoise. La formation à l'enseignement des sciences: le virage épistémologique. Didaskalia, Lyon (France), v. 1, n. 1, p. 49-68, septembre 1993.

DÉSAUTELS, Jacques; LAROCHELLE, Marie. L'enseignement des sciences. Québec (Canada): Les Presses de l'Université Laval, 1995.

DURKHEIM, Émile. As regras do método sociológico. In: Durkheim. São Paulo: Abril Cultural, 1978 (Coleção Os Pensadores), p. 46-61.

FOUREZ, Gérard. A construção das ciências: introdução à filosofia e à ética das ciências. São Paulo: Edunesp, 1995.

GIBBONS, Michael; LIMOGES, Camille.; NOWOTNY, Helga.; SCHWARTZMAN, Simon; SCOTT, Peter.; TROW, Martin. The new production of knowledge: the dynamics of science and research in the contemporary societies. Londres: Sage, 1994.

GUILBERT, Louise; MELOCHE, Danielle. L'idée de science chez des enseignants en formation: un lien entre l'histoire des sciences et l'hétérogénéité des visions? Didaskalia, Lyon (France), v. 1, n. 2, p. 7-30, décembre 1993. 
HOBSBAWM, Eric J. A era dos extremos. São Paulo: Companhia das Letras, 1995.

JODELET, Denise. Représentation sociale: phénomène, concept et théorie. In: MOSCOVICI, Serge (Org.). Psychologie sociale. Paris: PUF, 1991, p. 23-42.

KNORR-CETINA, Karin. The manufacture of knowledge: an essay on the constructivist and contextual nature of science. Oxford: Pergaman Press, 1981.

KRASILCHIK, Myriam. O professor e o currículo de ciências. São Paulo: Edusp, 1987.

LÉVY, Pierre. Cibercultura. São Paulo: Editora 34, 1999.

MCDERMOTT, Lillian C. A perspective on teacher preparation in physics - other sciences: the need for special science courses for teachers. American Journal of Physics, Boston (USA), v. 58, n. 8, p. 734-742, 1990.

MORENO MARINON, Mariano. Ciencia y construcción del pensamiento. Enseñanza de las Ciências, Barcelona (España), v. 4, n. 1, p. 57-63, 1986.

MORGAN, Kevin. Teacher and leadership education for scientific and technological literacy, Fórum Project 2000+, Paris: Unesco, july 1993.

MOSCOVICI, Serge. A representação social da psicanálise. Rio de Janeiro: Zahar, 1978.

. The phenomenon of social representations. In: FARR, Robert; MOSCOVICI, Serge. (Eds.). Social representations. Cambridge: Cambridge University Press, 1984, p. 33-45.

ROSENBERG, Nathan. Inside the black box: technology and economics of industrial innovation. Harmondsworth: Penguin, 1982.

SANTOS, Boaventura de Sousa. Pela mão de Alice. O social e o político na pós-modernidade. São Paulo: Cortez, 1995.

SANTOS, Gilberto Lacerda. As representaçôes de professores de ciências sobre a tecnologia. Anais do IV Congresso de Iniciação Científica da Universidade de Brasília. Brasília: Universidade de Brasília, 1997.

; BRUZZI, Rita Carolina Vereza. Uma abordagem histórico-crítica de ciência e tecnologia como estratégia para a alfabetização científica e tecnológica. Linhas Críticas, Brasília. v. 2-3, n. 3-4, p. 131-138, 1997.

SCHAFF, Adam. A sociedade informática. São Paulo: Edunesp, 1995.

SOBRAL, Fernanda A. F. Novas tendências do desenvolvimento científico e tecnológico. Correio Brasiliense, Brasília, 18 jun. 2000, p. 16.

SOLTMAN, Jean-Paul. L’alphabétisation scientifique et technologique pour le développement. Anais do Fórum 2000+, Paris: Unesco, 1993.

TRIGUEIRO, Michelângelo; FIGUEIREDO, Vilma. O desenvolvimento científico-tecnológico atual, globalização e democratização: dilemas e perspectivas. In: SOBRAL, Fernanda A. F.; MACIEL, Maria; TRIGUEIRO, Michelângelo. A alavanca de Arquimedes: ciência e tecnologia na virada do século. Brasília: Paralelo 15, 1998, p. 81-97.

WALKS, Louis. STS: Une nouvelle éthique de l'enseignement scientifique et technologique aux États-Unis. In: FOUREZ, Gérard (Org.). Construire une éthique de l'enseignement scientifique. Namur (Belgique): Presses Universitaires de Namur, 1986, p. 46-67.

YARDLEY, Li. Sciente, technology and social change. Londres: Unwin Kyman, 1988. 


\section{Technology, science and their production mode: primary school teachers' representations} Abstract

This paper presents the findings of research aimed at making explicit the representations of future science teachers, students at three important Brazilian universities, being trained to teach in the first four grades of primary schools, (Pedagogy course) concerning Science, Technology and their production mode. The conclusions to which we have come show that the future Brazilian Science teachers are far from performing adequately according to the New Mode of Knowledge Production and that there is need to adopt a New Training Mode, as a fundamental strategy to enable the new generations to acquire an understanding of technological and scientific undertaking as these new generations are currently being taught by means of traditional scientific and technological training and therefore end up inserted in a vicious circle characterized by a systematic lack of interest for contents of scientific and technological nature and by the incomprehension of the social nature of such contents.

Keywords: Teacher training. Science and technology. New mode of knowledge production.

\section{Technologie, science et leur mode de production : la représentation des maîtres de l'enseignement primaire}

Résumé

Ce travail présente des résultats d'une recherche qui vise à rendre explicites les représentations des futurs maîtres de science à trois importantes universités brésiliennes, en formation pour travailler dans les quatre premières années de l'enseignement primaire (cours de Pédagogie), en ce qui concerne la science, la technologie et leur mode de production. Les conclusions auxquelles nous sommes arrivés montrent que les futurs maîtres en science sont loin de pouvoir travailler selon le Nouveau Mode de Production du Savoir et qu'il est nécessaire d'adopter un Nouveau Mode de Formation comme stratégie fondamentale pour instrumentaliser adéquatement les nouvelles générations pour la compréhension de l'entreprise technologique et scientifique car les nouvelles générations sont actuellement enseignées par des méthodes traditionnelles de formation technologique et scientifique, ce qui les insèrent dans un cercle vicieux charactérisé par un manque systématique d'intérêt dans les contenus de nature scientifique et technologique et par l'incompréhension de la nature sociale de tels contenus.

Mots clefs : Formation de maîtres. Science et technologie. Nouveau mode de production du savoir.

\section{La tecnología, la ciencia y su modo de producción: representaciones de profesores de la enseñanza fundamental}

\section{Resumen}

Este trabajo presenta resultados de una investigación cuyo objectivo fue la explicitación de representaciones de futuros profesores de ciencias de tres importantes universidades brasileñas, en formación para actuar en los cuatro primeros años de la enseñanza fundamental (licenciatura en pedagogía), acerca de la ciencia, de la tecnología y de su modo de producción. Las conclusiones indican que los futuros profesores de ciencias brasileños están distantes de una actuación pertinente con el nuevo modo de producción del conocimiento y que es necesaria la adopción de un nuevo modo de formación, estrategia fundamental para instrumentalizar adecuadamente las nuevas generaciones para la compreensión del emprendimiento científicotecnológico, nuevas generaciones esas que, por medio del modo tradicional de formación científica y tecnológica, acaban inseridas en un círculo vicioso pautado sea por el desinterés sistemático por contenidos de naturaleza científica y tecnológica, sea por la incomprensión de la naturaleza social de estes contenidos. Palabras-clave: Formación de profesores. Ciencia y tecnología. Nuevo modo de producción del conocimiento.

Recebido: 12.01.2007

Aceito: 23.04.2007

Linhas Críticas, Brasília, v. I3, n. 24, p. 2I-36, jan./jun. 2007 